\title{
$\mathrm{NIH}$ hopes to see more bang for the same buck
}

resident Bush's proposed 2006 budget for the NIH will remain virtually unchanged from the current fiscal year. After the budget doubled in the 5 years between 1998 and 2003 , the current financial plan is to increase $\mathrm{NIH}$ allocations by only $0.7 \%$, to $\$ 28.8$ billion. This falls far below the expected inflation rate of $3.5 \%$ for biomedical research and amounts to an increase of just \$196 million. While most NIH researchers are not surprised by this news, which was announced in February, concerns are still being raised.

Andrew C. Baldus, the assistant director for budget at the NIH, told the JCI that the top priority is to support the NIH Roadmap for medical research. Funding for the Roadmap will increase by $\$ 98$ million in 2006 to support its 3 main aims: generation of new knowledge, fostering of multidisciplinary research teams, and organization of a new infrastructure to facilitate bench-tobedside translation of new discoveries.

The National Institute for Allergy and Infectious Diseases Biodefense Research program will also have increased appropriations to be used for vaccine and drug development to aid in the fight against potential bioweapons. The Neuroscience Blueprint and AIDS research programs will also see small increases in funding. At this time, Baldus could not say whether any programs or agencies would suffer cutbacks as a result of the new budget.

But the number of full-time postdoctoral training positions will be reduced. In 2006, the NIH plans to support 17,442 trainees for $\$ 764$ million, a reduction of 397 full-time positions funded in 2005. Baldus explained that these postdoctoral awards "are a priority, but choices had to be made. The tradeoff was increasing the stipend by $4 \%$ to where it needs to be and offering better health benefits, but having fewer fellows.”

"I believe most biomedical scientists are very disappointed in the [NIH budget] proposed by the President," says H. George Mandel, chairman of the National Caucus of Basic Biomedical Science Chairs, an organization comprising faculty from US medical schools that meets with political leaders to discuss the importance of health research and a realistic budget for the NIH. "It is too early to realize the final outcome of future deliberations in the Congress," Mandel continues, "but the likely end result may well be less than what scientists consider a mere inflationary increase. The opportunities for improved health, opened by recent discoveries, and the continuing need to attract bright young students into science, need to be recognized by our government. Our nation's future depends on our leadership in science and technology."

It is clear that NIH scientists are pleased that the budget was doubled over the past few years and recognize that the budgetary situation at other agencies, such as the Centers for Disease Control, is much worse than at the NIH. However, many NIH scientists are cutting back on attendance at national meetings and recruiting summer students into the labs in order to make ends meet. "We expect to be able to maintain our research at the same pace as over the last few years," one researcher said, "but the key question is how long the budget situation will last.”

\section{Stacie Bloom}

\section{Nabel speaks up about directing the NHLBI}

1

he National Heart, Lung, and Blood Institute (NHLBI) covers extensive ground, exploring causes, prevention, therapy, and diagnosis of diseases involving the heart, blood, blood vessels, and lung. The NHLBI also researches sleep disorders and coordinates the NIH Woman's Health Initiative. Elizabeth Nabel, formerly the scientific director of clinical research in the NHLBI intramural program and a board-certified cardiologist, is now at its helm.

In her new role, Nabel manages nearly 850 federal employees and an annual budget of about $\$ 3$ billion. The JCI talked to Nabel about her new responsibilities and the goals she hopes to reach as director of the NHLBI.

JCI: How were you selected for this new position?

Nabel: There was a national search lead by two NIH institute directors. The search committee was comprised of scientists from around the country. The search committee provided recommendations to [NIH Director Elias] Zerhouni who made the selection.

JCI: What is the duration of the position?

Nabel: The position is open ended with a review every 5 years.

JCI: What are your top objectives as director of the NHLBI?

Nabel: To stimulate basic discoveries through innovation, creativity, and using the most advanced biomedical technologies. To speed translation to clinical applications so that people can benefit as quickly as possible. To facilitate communication between scientists and physicians so that new ideas can be generated, shared, and advanced; in addition, to effectively communicate research advances to the public to improve their understanding of new promising science.
JCI: What do you consider the biggest health threat in your field?

Nabel: Our biggest health threat is the tremendous increase in obesity in this country which will threaten the health gains that we have made in cardiovascular diseases over the past 3 decades.

JCI: What do you think is your biggest challenge in this position?

Nabel: I want the NHLBI to support the most promising research in this country in heart, lung, and blood diseases. My goal is to support investigators who will make critically important new basic discoveries as well as investigators who will then translate those discoveries into new therapies. We must recruit and train the next generation of physician-scientists in this country and provide them with the independence and skills to be our next scientific leaders.

JCI: When you leave, what do you hope to have accomplished?

Nabel: I want to raise the profile of the NHLBI so that the public will have an understanding of the research advances fostered by the NHLBI, and so that our institute is viewed as providing outstanding leadership in this country on critical issues facing us. Ultimately, our mission is to serve the public and to improve individual and public health. My job is to shepherd this institute in new emerging areas of science, with a continual emphasis on excellence.

\section{Stacie Bloom}

